\title{
mTHPC-based photodynamic therapy induction of autophagy and apoptosis in cultured cells in relation to mitochondria and endoplasmic reticulum stress
}

\author{
AURÉLIE FRANÇOIS, SOPHIE MARCHAL, FRANÇOIS GUILLEMIN and LINA BEZDETNAYA
}

CRAN-CNRS UMR 7039 Nancy-University, Centre Alexis Vautrin,

Avenue de Bourgogne, 54511 Vandoeuvre-lès-Nancy, France

Received June 7, 2011; Accepted July 15, 2011

DOI: $10.3892 /$ ijo.2011.1174

\begin{abstract}
Photodynamic therapy (PDT), an approved anticancer treatment, is reported as a potent inducer of programmed cell death (PCD) by both apoptosis and autophagy. The present study investigated the kinetics of both autophagy and caspase activation in MCF-7 cells submitted to MTHPC-PDT upon condition of treatment promoting ER accumulation of mTHPC. Fluence-dependent immediate cytochrome c (cyt C) release followed by caspase- 9 and -7 activation at $1 \mathrm{~h}$ post-PDT evidenced a mitochondrial oxidative stress triggered by high light doses leading to $>90 \%$ of cell death. ER oxidative stress was monitored by the induction of the glucose-related protein chaperone GRP78. From 6 h post-PDT, GRP78 induction was accompanied by the conversion of LC3-I into LC3-II, the hallmark of autophagosome formation. The formation of acid vesicles evidenced by fluorescence microscopy was obvious from $22 \mathrm{~h}$ post-PDT. Twenty-four hours post-PDT, cyt C release decreased and caspase- 9 cleavage disappeared, while the expression of cleaved caspase-7 remained significant. At the same time, the profiles of GRP78, cleaved caspase-7 and LC3-II expression were similar irrespective of light doses. In contrast to an inhibitor of caspase activation Z-VAD-FMK, the use of autophagy inhibitor, Wortmannin, impaired cytotoxicity along with an increase in caspase-7 activation. These results demonstrate a valuable contribution of autophagy to cell death in mTHPC-photosensitized MCF-7 cells.
\end{abstract}

\section{Introduction}

Photodynamic therapy (PDT) has been approved as a treatment modality in various cancerous and non-cancerous lesions

Correspondence to: Aurélie François, CRAN-CNRS UMR7039 Nancy-University, Centre Alexis Vautrin, Avenue de Bourgogne, 54511 Vandoeuvre-lès-Nancy, France

E-mail: a.francois@nancy.unicancer.fr

Key words: photodynamic therapy, mTHPC, autophagy, apoptosis, ER oxidative stress, caspases
(1). The direct cytotoxic effect of PDT is the result of lightinduced generation of reactive oxygen species (ROS), which cause irreparable damage in a close proximity of their generation, eventually leading to apoptotic and/or necrotic cell death (2). PDT is known as a potent inducer of apoptosis in many types of cells (3-5). Recent evidence indicates that the second type of programmed cell death (PCD), namely autophagy, may be induced by PDT (6-10). Autophagy is developed by cells into an attempt to repair and survive photodamage to key organelles but could be turned into a cell death signal if initial response fails $(9,11)$. Autophagic cell death is a process including lysosome-dependent protein degradation and organelle turnover characterised by highly-vacuolated cells. It starts with the formation of a double-membrane structure that wraps cytoplasmic components as well as organelles, to shape vacuoles called autophagosomes (reviewed in ref. 12). This type of cell death can occur in case of sustained oxidative stress produced in mitochondria (13-16) or endoplasmic reticulum (7,17). In most cases, autophagic cell death has been reported to be an alternative cell death pathway in cells with defects in factors that mediate apoptosis (reviewed in refs. 9,18).

Following PDT, autophagy has been demonstrated to be an alternative cell death pathway in Bax/Bak-deficient cells $(7,8,10)$. Inactivation or photodamage of $\mathrm{Bcl}-2$ was also reported to increase autophagy induced by PDT $(10,19)$. However, although autophagy was enhanced when apoptosis was impaired, Kessel et al have reported that autophagy accompanied apoptosis in photosensitized leukaemia cells (8). Recent observation of Sasnauskiene et al (20) also demonstrated both cell death modalities after mTHPC photosensitization of squamous carcinoma monolayer cells upon the condition of MTHPC diffuse localisation. Our previous studies $(21,22)$ established that endoplasmic reticulum (ER) is one of the preferential sites of mTHPC $\left(\right.$ Foscan $\left.^{\circledR}\right)$ localisation especially after an extended time of contact ( $24 \mathrm{~h}$ ) of the photosensitizer with cells (21). Upon this condition, PDT promoted ER oxidative stress whose intensity corresponded to the extent of caspase-7 activation in caspase-3 deficient MCF-7 cells (21). The present study investigated autophagy and apoptosis induction in MCF-7 cells subjected to mTHPC-based PDT. With this goal we defined the schedule of both caspase activation and autophagosome formation in relation to oxidative stress 
in ER and mitochondria. Finally, their respective impact on photo-induced cell death was assessed.

\section{Materials and methods}

Cell culture. The human breast adenocarcinoma cell line MCF-7 was grown as a monolayer in phenol red-free RPMI-1640 medium (Invitrogen, Cergy-Pontoise, France) supplemented

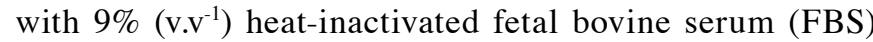
(PAN Biotech GmbH, Aidenbach, Germany), $1 \%\left(\mathrm{v} . \mathrm{V}^{-1}\right)$ penicillin (10,000 IU), streptomycin (10,000 mg.ml $\left.{ }^{-1}\right)$ and $1 \%\left(\mathrm{v} . \mathrm{v}^{-1}\right)$ glutamin $200 \times 10^{-3} \mathrm{M}$ (Invitrogen). Cells were maintained at $37^{\circ} \mathrm{C}$ in a humidified $5 \% \mathrm{CO}_{2}$ atmosphere and routinely subcultured every 7 days.

PDT protocols. MCF-7 cells were seeded in Petri dishes at $4 \times 10^{4}$ cell. $\mathrm{ml}^{-1}$, or in SlideFlasks at $10^{4}$ cell. $\mathrm{ml}^{-1}, 4$ days before mTHPC sensitization. mTHPC was provided by Biolitec AG (Jena, Germany). mTHPC stock solution in methanol $\left(6 \times 10^{-3} \mathrm{M}\right)$ was diluted in medium supplemented with $2 \%\left(\mathrm{v} \cdot \mathrm{v}^{-1}\right) \mathrm{FBS}$ and added to the cell culture to reach the final concentration of $1.5 \times 10^{-6} \mathrm{M}$. After $24 \mathrm{~h}$ of incubation, cells were washed and subjected to a red laser light source $(650 \mathrm{~nm})$ (Spectra-Physics Lasers, Mountain View, CA, USA) at fluence ranging from 0.01

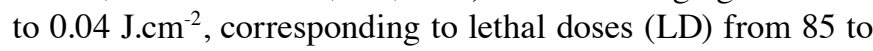
$95 \%$, as was shown previously by clonogenic assays (21). When the use of apoptosis or autophagy inhibitors was required, they were added to the exponentially growing cell culture $30 \mathrm{~min}$ before irradiation and maintained in contact with cells until analysis. A $10^{-2} \mathrm{M}$ stock solution in DMSO of the caspase inhibitor Z-VAD-FMK (BD Biosciences, Le-Pont-de-Claix, France) was added to the medium of control and PDT-treated cells to the final concentration of $2 \times 10^{-5} \mathrm{M}$. To study the effect of autophagy inhibition, Wortmannin (Sigma-Aldrich, Saint Quentin Fallavier, France) was dissolved at $10^{-3} \mathrm{M}$ in DMSO and added to cells at a final concentration of $2.5 \times 10^{-7} \mathrm{M}$. Likewise, the lysosome-neutralizing agent $\mathrm{NH}_{4} \mathrm{Cl}$ (VWR, Fontenay sous Bois, France) was prepared at $10^{-2} \mathrm{M}$ in water, adjusted to neutral $\mathrm{pH}$ and filtered before being used in the experiments.

Fluorescence microscopy for visualisation of MDC-labelled vacuoles. A stock solution of monodansylcadaverin (MDC) (Sigma-Aldrich) was prepared in acetic acid at $3 \times 10^{-2} \mathrm{M}$. At different times post-irradiation, cells submitted to an $\mathrm{LD}_{85}$ PDT dose were incubated with $5 \times 10^{-5} \mathrm{M}$ MDC in medium

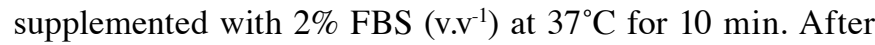
washing, the intracellular MDC-fluorescence was immediately observed (excitation filter 330-385 nm, emission filter 510-550 nm) using an upright epifluorescence microscope (AX-70 Provis, Olympus, Rungis, France) equipped with a 100-W mercury vapor lamp and a Peltier cooled CCD camera (DP50, Olympus). Control cells were sensitized with mTHPC for $24 \mathrm{~h}$ but non irradiated. Fluorescence images were recorded using $\mathrm{x} 40$ and $\mathrm{x} 100$ enlargement. To verify the staining of MDC, we incubated $\mathrm{NH}_{4} \mathrm{Cl}\left(10^{-2} \mathrm{M}\right)$ and Wortmannin $\left(2.5 \times 10^{-7}\right.$ M) for the last $30 \mathrm{~min}$ of mTHPC incubation. Photosensitized cells, treated or not with inhibitors, were then subjected to LD85 PDT-dose and kept in an incubator for $22 \mathrm{~h}$ until MDC labelling. Fluorescence intensity was quantified by ImageJ software by demarcating the Region of Interest (ROI) in 10 individual cells.

Total protein extracts. mTHPC-sensitized MCF-7 cells, cultured in Petri dishes, incubated or not with apoptosis and autophagy inhibitors, were treated by PDT, and maintained at $37^{\circ} \mathrm{C}$, in $5 \%$ $\mathrm{CO}_{2}$ humidified atmosphere until analysis. As described previously (21), at different times post-PDT, from 0 to $24 \mathrm{~h}$, both adherent and floating cells were solubilized with ice-cold lysis buffer containing $10^{-2} \mathrm{M}$ Tris- $\mathrm{HCl} \mathrm{pH}$ 7.4, $1 \%$ Triton X-100, $10^{-3} \mathrm{M}$ EDTA and $6 \times 10^{-2} \mathrm{M}$ phenylmethylsulfonylfluoride (PMSF). Extracted proteins were removed by centrifugation at $15,000 \mathrm{x} \mathrm{g}$ for $30 \mathrm{~min}$.

Isolation of endoplasmic reticulum. Treated MCF-7 cells were removed using a cell scrapper and suspended in saccharose buffer $\left(10^{-2} \mathrm{M}\right.$ HEPES, $2.5 \times 10^{-2} \mathrm{M}$ sucrose $)$. Cell membranes were disrupted. Suspension was centrifuged for $15 \mathrm{~min}$ at $15,000 \times \mathrm{g}$ to eliminate nuclei, mitochondria and unbroken cells. The resulting supernatant was further centrifuged at $130,000 \mathrm{x} \mathrm{g}$ for $90 \mathrm{~min}$ at $4^{\circ} \mathrm{C}$. The supernatant was collected as the cytosolic fraction and the microsomal pellet (ER fraction) was resuspended in $200 \mu 1$ lysis buffer. This fraction was subjected to Western blot analysis for GRP78 protein. ER samples were analysed for mitochondrial contamination by Western blotting using mitochondria-marker Tom 40 (Tebu-bio). No detectable antibody expression was noted in ER extracts, thus indicating the lack of contamination (data not shown).

Western blot analysis. Protein concentration was determined by the DC Protein Assay from BioRad (Marnes-la-Coquette, France). Equal amounts of protein were loaded onto appropriate polyacrylamide gels (SDS-PAGE), subjected to electrophoresis, transferred to a PVDF membrane (GE Healthcare, Orsay, France). After blocking with a 5\% (or 10\% in the case of LC3) $\mathrm{w} / \mathrm{v}$ solution of non-fat powered milk in TBST ( $\mathrm{pH}$ 7.6), the membrane was probed with designated first antibody overnight at $4^{\circ} \mathrm{C}$, followed by a 1-h incubation with a horseradish peroxidase (HRP)-conjugated secondary antibody at room temperature. Antibodies used were the rabbit anti-LC3 antibody (Novus Biologicals, Littleton, CO, USA), the rabbit anti-cleaved caspases-7 and -9, purchased from Cell Signaling (Danvers, MA, USA), the mouse anti-Bip/GRP78 (BD Biosciences), the mouse anti-cyt $C$ (BioLegend, San Diego, CA, USA) and the rabbit anti-tubulin (Santa Cruz Biotechnology, Santa Cruz CA). The mouse anti-cleaved PARP antibody was provided with an extract of Jurkat cells treated with camptothecin as a positive apoptotic control (BD Biosciences). The anti-mouse and anti-rabbit secondary antibodies conjugated to HRP were both obtained from Cell Signaling. Tubulin antibody was used as an internal protein loading control. The immune complexes were detected by enhanced chemiluminescence system (GE Healthcare, Orsay, France) and revealed by autoradiography. The band density was quantified using the ImageJ software and normalized to that of the control group.

Semi-quantification of autophagy. One of the hallmarks of autophagy is the conversion of the microtubule-associated protein-1 light chain-3, LC3-I into LC3-II, which participates in the formation of autophagosomes and is associated with 


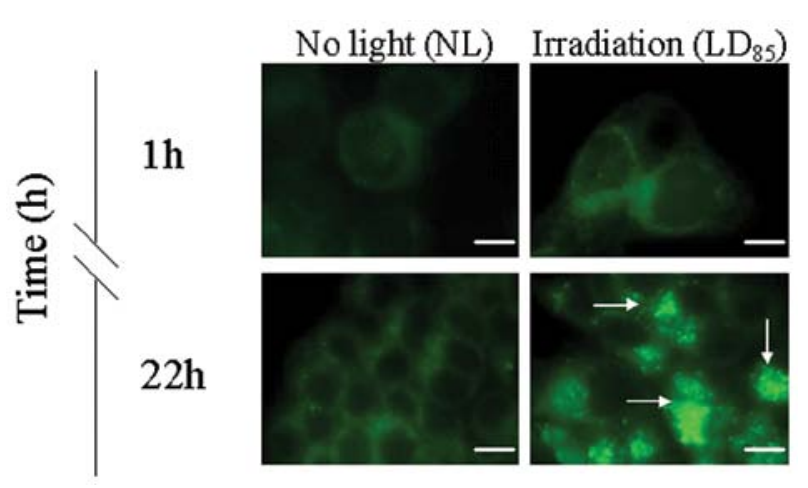

Figure 1. MDC-labelled autophagic vacuoles in mTHPC-PDT-treated MCF-7 cells observed by fluorescence microscopy. MCF-7 cells, cultured in slideflasks, were sensitized with $1.5 \times 10^{-6} \mathrm{M}$ mTHPC for $24 \mathrm{~h}$ and subjected to $8 \times 10^{-3}$

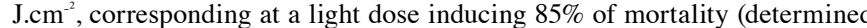
by clonogenic assays). At different times after irradiation, photosensitized MCF-7 cells were loaded with $5 \times 10^{-5} \mathrm{M}$ MDC for $10 \mathrm{~min}$ at $37^{\circ} \mathrm{C}$ and observed by fluorescence microscopy, with an excitation filter between 330 and $385 \mathrm{~nm}$ and an emission filter of 510-550 $\mathrm{nm}$. Control cells (NL) were subjected to mTHPC only (drug, no light) and were stained with MDC for indicated times after the end of the sensitization. Arrows indicate acidic vacuoles suggested by punctuated MDC labelling in the cytoplasm. Micrographs are representative of three independent experiments. White bar, $10 \mu \mathrm{m}$.

\section{Irradiation $\left(\mathrm{LD}_{85}\right)$}

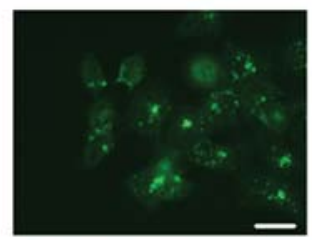

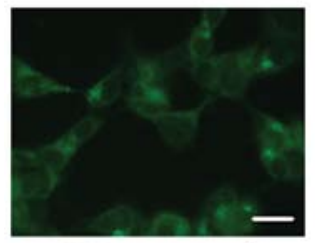

+ Wortmannin

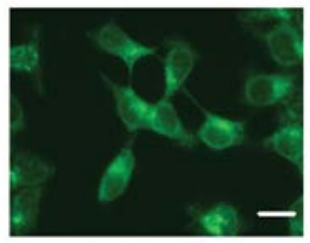

$+\mathrm{NH}_{4} \mathrm{Cl}$
Figure 2. MDC incorporation in the presence of autophagy inhibitors. Cells were treated with Wortmannin $\left(2.5 \times 10^{-7} \mathrm{M}\right)$ or $\mathrm{NH} 4 \mathrm{Cl}\left(10^{-2} \mathrm{M}\right) 30 \mathrm{~min}$ before LD85 PDT-dose and labelled with MDC $22 \mathrm{~h}$ post-treatment. Images were compared with those irradiated at LD85. White bar, $20 \mu \mathrm{m}$. Representative of three separate experiments.

their structure after processing (23). The ratio LC3-II/LC3-I is a sensitive index of macroautophagy and is an easy and quick semi-quantitative method for monitoring its regulation $(24,25)$. Semi-quantification of the ratio LC3-II/LC3-I/tubulin was performed using Image J software and normalised to that of drug control (NL). To inhibit hydrolysis of LC3-II by lysosomal proteases, incubation buffers were supplemented with a combination of $10 \mathrm{mg} / \mathrm{ml}$ protease inhibitors E64d and Pepstatin A. Inhibitors were prepared in DMSO at concentration of $10 \mathrm{mg} / \mathrm{ml}$ each. Inhibitors were added to cell media $30 \mathrm{~min}$ before irradiation and remained in the growth media for $24 \mathrm{~h}$.
Cytotoxicity assay. mTHPC-photosensitized MCF-7 cells with $0.01,0.02$ and $0.04{\mathrm{~J} . \mathrm{cm}^{-2}}^{2}$, leading to 85,90 and $95 \%$ of mortality respectively, as previously determined by clonogenic assays, were trypsinized and dispensed in 96-well plates at a density of $10^{4}$ cells per well, with or without inhibitors. After $24 \mathrm{~h}$ of culture, cytotoxicity was measured using a tetrazolium salt MTT (Sigma-Aldrich). Resulting crystals were dissolved with $20 \%$ sodium dodecyl sulfate (SDS, Sigma-Aldrich). The absorbance value was measured using a plate microreader (MultiSkan MCC 340, Labsystems, Cergy-Pontoise, Val d'Oise, France). The toxicity data for cells exposed to inhibitors were normalized to that of the corresponding drug control. Data are the mean $\pm \mathrm{SD}$ of the results of at least three independent experiments.

Statistical analysis. The data were expressed as means \pm SD (standard deviation). Mann-Whitney's U-test was performed using Statview 5.0 software and significance was assumed at $\mathrm{p}=0.05$.

\section{Results}

Post-PDT kinetics of autophagy in MCF-7 submitted to $m T H P C-P D T$. To ascertain the induction of autophagy by mTHPC-PDT, fluorescence microscopy analysis was performed using the MDC at different times after PDT dose leading to $85 \%$ of cell death $\left(\mathrm{LD}_{85}\right)$. MDC, which marks acidic organelles (26), could be also used for imaging of enhanced lysosomal activity and lysosome-autophagosome fusion products visualized as distinct dot-like structures according to the method of Biederbick et al (27). The eventual interference between mTHPC and MDC fluorescence was investigated. Although the technical datasheet refers to no overlap between the spectra of MTHPC and that of MDC, we have verified that spots of MDC fluorescence did not correspond to MTHPC fluorescence (data not shown).

Control cells showed mainly a uniformly diffuse distribution of MDC supporting that mTHPC alone did not induce autophagy (Fig. 1). PDT-treated cells were examined at 1, 6, 18, 20, 22 and $24 \mathrm{~h}$ after irradiation. MDC fluorescence pattern at $1 \mathrm{~h}$ post-irradiation (Fig. 1) along with time points until $22 \mathrm{~h}$ was not significantly different from control cells (data not shown). On the contrary, in long-term incubation, the punctiforme spots of MDC (arrows) were increasingly distributed in the cytoplasm or in the perinuclear regions (Fig. 1). The analysis of fluorescence intensities indicates that there was approximately a two-fold increase in the fluorescent bright dots at $22 \mathrm{~h}$ compared to $1 \mathrm{~h}$ post-PDT. The fluorescence intensities measured in 10 cells increase from 5.16 \pm 3.28 (AU) in control cells to $13.74 \pm 6.34(\mathrm{AU})$ at $1 \mathrm{~h}$ post-PDT and $29.89 \pm 12.36$ (AU) at $22 \mathrm{~h}$ post-PDT.

The addition of lysosome neutralizing agent $\mathrm{NH}_{4} \mathrm{Cl}$ led to a drastic reduction in MDC punctual formation with a decrease to $12.77 \pm 2.35(\mathrm{AU})$ in fluorescence intensity in photosensitized MCF-7 cells compared with cells treated by mTHPC-PDT alone (Fig. 2). The presence of Wortmannin, a potent phosphatidylinositol (PI3-K) inhibitor that blocks autophagy at an early stage (28), also resulted in a diffuse intracellular distribution of MDC (Fig. 2), with a fluorescence intensity reduced to $14.93 \pm 3.98$ (AU). 


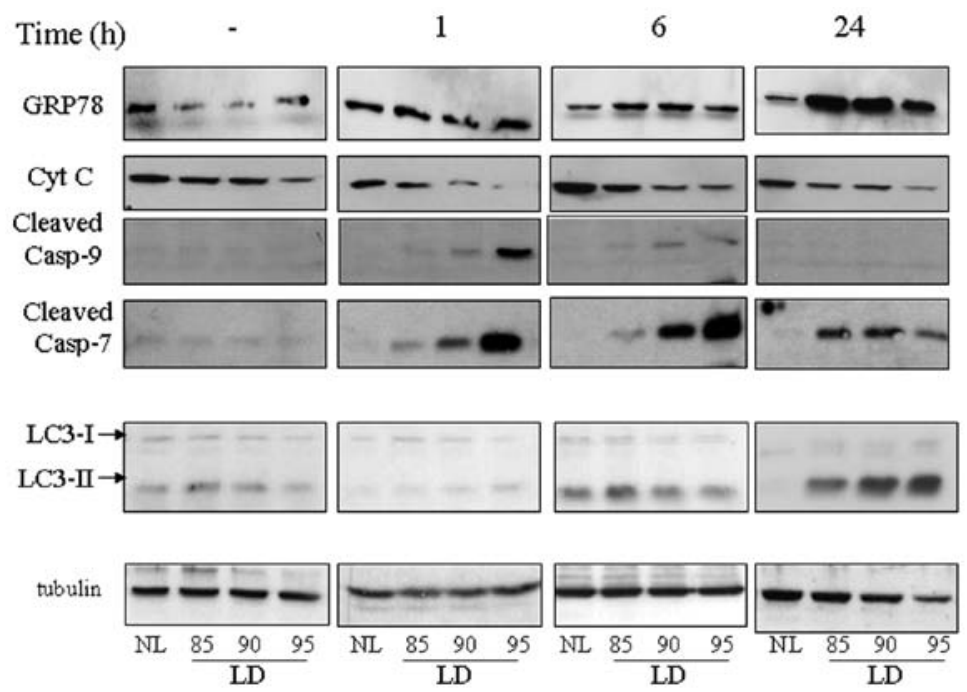

Figure 3. Kinetics of caspase activation and autophagy induction in relation to ER and mitochondria photooxidative stress. The analysis of GRP78, mitochondrial cytochrome C, cleaved caspases-9 and -7 and LC3-I and LC3-II expressions, was performed in MCF-7 cells incubated for $24 \mathrm{~h}$ with $1.5 \times 10^{-6} \mathrm{M} \mathrm{mTHPC}$ and irradiated at various fluences of red laser light. Protein expression was assessed by immunoblotting for GRP78 on ER and for all other proteins on whole cell extracts (as described in Materials and methods) over a 24-h time-course. Control cells (NL) were subjected to mTHPC only (drug, no light). Tubulin was used as a loading control.

Kinetics of caspase activation and autophagy induction in relation to ER and mitochondria photooxidative stress. MCF-7 cells were treated with increasing fluence inducing 85, 90 and 95\% mortality and then processed at different times post-irradiation (from few minutes to $24 \mathrm{~h}$ ) (Fig. 3). ER oxidative stress was evaluated by GRP78 induction, a stress-associated ER resident protein and by the loss of cytochrome $\mathrm{C}$ from mitochondria into the cytosol. The activation of post-mitochondrial events, represented by the expression of cleaved caspases- 9 and -7 was investigated. We also assessed the conversion of the protein LC3-I into LC3-II, one of the hallmarks of autophagy.

Immediately after cell photosensitization, notable changes were observed only for the loss of cytochrome $\mathrm{C}$ at the highest light dose $\left(\mathrm{LD}_{95}\right)$. Compared to control cells (non irradiated), the expression of cyt $\mathrm{C}$ decreased about 2-fold (established with ImageJ software, data not shown). At $1 \mathrm{~h}$ post PDT, cyt $\mathrm{C}$ loss was more pronounced (10-fold at LD95 as compared to NL, data not shown) and was accompanied by a dose-dependent activation of both caspases-9 and-7. Caspase-7-cleavage was further increased at $6 \mathrm{~h}$ post-PDT, especially for the two highest lethal doses $\left(\mathrm{LD}_{90}\right.$ and $\left.\mathrm{LD}_{95}\right)$. The cyt $\mathrm{C}$ release and activation of caspase-9 were diminished in comparison to $1 \mathrm{~h}$ after PDT. Six hours post-PDT also resulted in an upregulation of GRP78 for all the light fluences, from $1.3 \pm 0.2$ to $1.5 \pm 0.4$-fold as compared to the control. A significant overexpression of LC3-II, 3.5 \pm 1.1 -fold as compared to the control ( $\mathrm{p}<0.05$ ), was observed at $\mathrm{LD}_{85}$ whereas the $\mathrm{LC} 3$ conversion remained low when fluence increased. It should be noted that the lowest level of LC3-II expression at $\mathrm{LD}_{95}$ coincided with the highest expression of cleaved caspase-7. The measurements carried out $24 \mathrm{~h}$ post-PDT confirmed the further diminution of the cyt $\mathrm{C}$ release and caspase- 9 activation, already observed at $6 \mathrm{~h}$ postPDT. This decline was accompanied by a decrease in cleaved caspase-7 expression at high light doses. However, caspase-7 remained at a significant level of expression $(\sim 7.45 \pm 3.1$-fold as compared to control) whatever the fluence applied. At the same time, we observed an increase in GRP78 and LC3-II expressions irrespective of the fluence applied (respectively $3.67 \pm 1.08$ and 5.5 \pm 0.61 -fold as compared to the NL). Since LC3-II can be itself degraded by autophagy, two protease inhibitors, E64d and Pepstatin A, were used to partially inhibit degradation of LC3-II. The presence of protease inhibitors did not affect the photo-induced increase in LC3-II at $24 \mathrm{~h}$ post-PDT (data not shown), thus pointing out LC3-II degradation blockade.

Effect of the caspase inhibitor Z-VAD-FMK on the expression of cleaved caspases-9 and -7, LC3-II and cell viability. We verified the inhibition of the proteolytic cascade by using a broadly selective caspase inhibitor,Z-VAD-FMK that irreversibly binds to the catalytic site of caspase proteases and inhibits apoptosis. In presence of the latter ( $20 \mu \mathrm{M}$ from $30 \mathrm{~min}$ before PDT to 6 or $24 \mathrm{~h}$ post-PDT), the absence of cleaved caspase- 9 and -7 expression was confirmed irrespectively to the fluence applied (Fig. 4A and B). Cells preloaded with Z-VAD-FMK displayed the persistence of autophagy especially at the lowest light dose $\left(\mathrm{LD}_{85}\right)$ while LC3-II expression decreased with light doses (Fig. 4C). We also noted that $24 \mathrm{~h}$ cell incubation with Z-VAD-FMK produced an intensive accumulation of LC3-II in non-irradiated cells. Suppression of caspase activation by adding Z-VAD-FMK slightly decreased photocytotoxicity, assessed by MTT test $24 \mathrm{~h}$ post-PDT (Fig. 4D). The percentages of dead cells in the presence of Z-VAD-FMK were respectively $59.71 \pm 23.15 \%\left(0.01 \mathrm{~J} . c m^{-2}\right), 54.15 \pm 7.87 \%(0.02 \mathrm{~J}$. $\left.\mathrm{cm}^{-2}\right)$ and $61.83 \pm 12.99 \%\left(0.04 \mathrm{~J} . \mathrm{cm}^{-2}\right)$ as compared to cell toxicity after PDT alone $(71.88 \pm 2.71,66.90 \pm 7.94 \%$ at $0.02 \mathrm{~J} /$ $\mathrm{cm}^{2}$ and $65.81 \pm 7.42 \%$ for respective light doses. Except for $0.02 \mathrm{~J} / \mathrm{cm}^{2}$ at which the values were found significantly different $(\mathrm{p}<0.05), \mathrm{Z}-\mathrm{VAD}$-FMK failed to protect cells from loss of viability after PDT. 


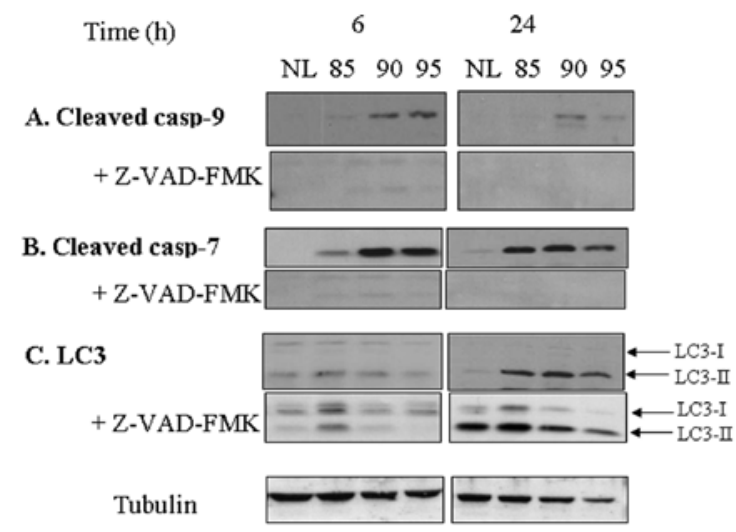

D. Cytotoxicity

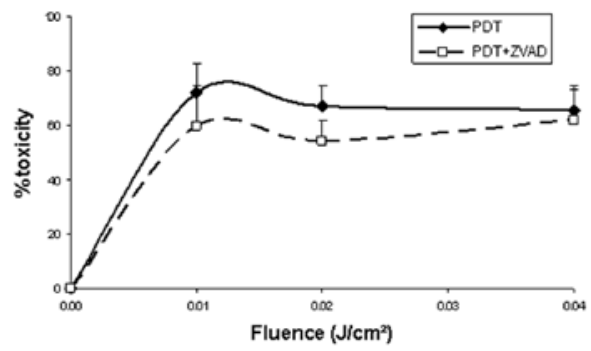

Figure 4. Effect of the inhibition of caspase activation on the expression of cleaved caspases-9 and -7, LC3-II and cell viability. The inhibition of caspase activation was performed with a broad spectrum caspase inhibitor, Z-VAD-FMK, at 6 and $24 \mathrm{~h}$ post-PDT. Cells were sensitized with $1.5 \times 10^{-6} \mathrm{M}$ mTHPC for $24 \mathrm{~h}$ and incubated with $2 \times 10^{-5} \mathrm{M}$ Z-VAD-FMK $30 \mathrm{~min}$ before the end of mTHPC sensitization. Cells were then subjected to a range of fluence from 0.01 to $0.04{\mathrm{~J} . \mathrm{cm}^{-2}}^{-2}$ and the inhibitor was kept in contact with cells until protein extraction performed at 6 and $24 \mathrm{~h}$ post-PDT. The specificity of the inhibition was verified through the analysis of the expression of cleaved caspases-9 (A) and -7 (B). Panel C displays the LC3 expression in the presence of Z-VAD-FMK assessed by Western blot analysis. Control cells (NL) were subjected to mTHPC only (drug, no light). Tubulin was used as a loading control for all Western blotting experiments. Fluence-dependent cytotoxicitywith and without Z-VAD-FMK was assessed by MTT test $24 \mathrm{~h}$ after photosensitization (panel D). The toxicity data for cells exposed to Z-VAD-FMK were normalized to that of the corresponding drug control. Results are the mean \pm SD of at least three independent experiments. " $p<0,05$, significantly different from control values, Mann Whitney's test.

Effect of the autophagy inhibitor Wortmannin on the expression of cleaved caspases-9 and -7, cleaved PARP, LC3-II and cell viability. As expected, in the presence of Wortmannin, LC3-I and LC3-II were barely detectable in protein cell extracts, indicating that LC3 conversion was inhibited at both times post-PDT ( 6 and $24 \mathrm{~h}$ ) (Fig. 5A). At $6 \mathrm{~h}$ post-PDT, the activation of cleaved caspases-9 and -7 in the presence of Wortmannin was shifted to the lowest light dose (Fig. 5B and C) showing an increase in the expression of cleaved caspase-9 and -7 at $\mathrm{LD}_{85}$. Considering that PARP is a highly specific substrate for caspase-7, we further tested PDT-induced PARP cleavage. The dose-response profile similar to caspase-7 expression was registered for PARP either in the absence or in the presence of Wortmannin (Fig. 5D), thus indicating the actual activity of caspase-7. Twenty-four hours post-PDT, low expression of cleaved caspase- 9 was observed at $\mathrm{LD}_{90}$ and $\mathrm{LD}_{95}$ without notable modification in caspase-7 expression and PARP cleavage (Fig. 5B-D). The presence of Wortmannin resulted in a significant decrease $(\mathrm{p}<0.05)$ in photocytotoxicity whatever the fluence applied (Fig. 5E). The percentages of

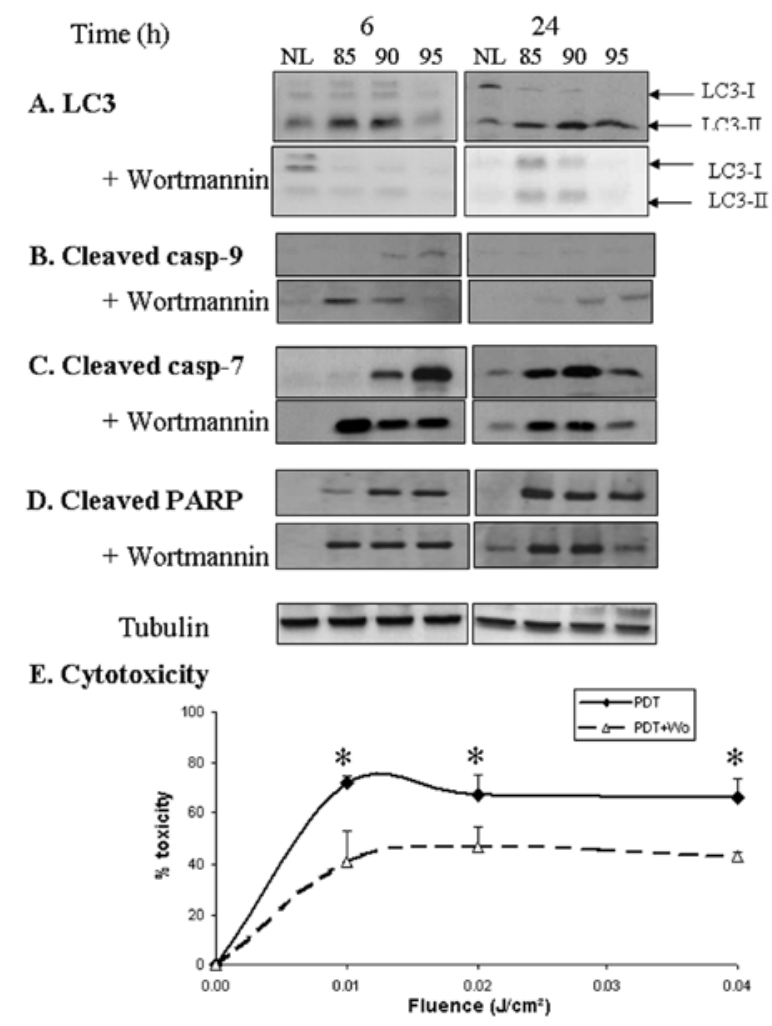

Figure 5. Effect of the inhibition of autophagy induction on the expression of cleaved caspase- 9 and -7, cleaved PARP, LC3-II and cell viability. Cells were sensitized with $1.5 \times 10^{-6} \mathrm{M}$ mTHPC for $24 \mathrm{~h}$ and incubated with $2.5 \times 10^{-7} \mathrm{M}$ of Wortmannin for $30 \mathrm{~min}$ before the end of mTHPC sensitization. Cells were then subjected to a range of fluence from 0.01 to $0.04 \mathrm{~J} . \mathrm{cm}^{-2}$ and the inhibitor was kept in contact with cells until protein extraction performed at 6 and $24 \mathrm{~h}$ post-PDT. Autophagy was analyzed by the Western blotting of LC3 conversion (A). At 6 and $24 \mathrm{~h}$ post-PDT, the effect of autophagy inhibition was studied on the cleavage of caspases-9, -7 and PARP by Western blotting (B-D). Control cells (NL) were subjected to mTHPC only (drug, no light). Tubulin was used as a loading control. Fluence-dependent photocytotoxicity with and without Wortmannin was assessed by MTT test $24 \mathrm{~h}$ after PDT (panel E). Results are the mean \pm SD of at least three independent experiments. ${ }^{*} \mathrm{p}<0.05$, significantly different from control values, Mann Whitney's test.

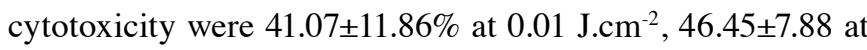
$0.02 \mathrm{~J} . c m^{-2}$ and $42.72 \pm 1.74 \%$ at $0.04 \mathrm{~J} . c m^{-2}$.

\section{Discussion}

Apoptosis and autophagy are types of PCD, which is an attractive tool to eliminate damaged and/or harmful cells, such as cancer cells in the course of radio- and chemotherapy. Numerous pieces of evidence indicate that cells preferentially die by apoptosis but, a defect in apoptosis may result in the induction of autophagy as an alternative cell death pathway (reviewed in ref. 29). Consistent with this observation, prominent autophagy was observed in caspase-3 deficient MCF-7 cells $(9,10)$ and in Bax/Bak lacking cells $(7,8,10)$ submitted to lethal PDT doses. However, PDT-induced autophagy was demonstrated even in apoptosis prone cells and as such autophagy is a common phenomenon $(8,10,20)$.

Our earlier studies showed that mTHPC-PDT is a moderate inducer of apoptosis in cultured tumor cells as well as in xenografts $(30,31)$. The present study demonstrated an appearance 
of distinct dots staining with MDC in MTHPC-photosensitized MCF-7 cells (Fig. 1). MDC staining must be interpreted with caution since MDC was described as a non-specific marker, which labels the acidic compartments comprised of late endosomes and lysosomes that have been freshly fused with autophagosomes (26). However, vanishing of the punctuate labelling in the presence of Wortmannin (Fig. 2) can be taken as a strong indication of mTHPC-photoinduced autophagy process.

The conversion of LC3-I to the autophagosomal membranebound form LC3-II is now widely used to monitor autophagy (23). Likewise, compared to LC3-I, LC3-II is more sensitive to immunoblot analysis as has been demonstrated in the study of Klionsky et al (32). Cells submitted to the lowest PDT-dose (LD85) displayed significant LC3-II expression but not pronounced cyt $\mathrm{C}$ release and caspase cleavage (Fig. 3). The achievement of the autophagic process in an absence of apoptosis was supported by the maintainence of LC3-II expression in presence of Z-VAD-FMK while caspases-9 and -7 cleavage was completely blocked (Fig. 4A-C). These results are in agreement with previous reports on PDT-treated cultured tumor cells, where autophagy features were reported while apoptosis was blocked $(8,10,19,33)$. Conversely, the inhibition of autophagy by Wortmannin promoted post-mitochondrial caspase activation and the subsequent cleavage of PARP (Fig. 5A-D). Taken together, these results confirm the assumption that apoptosis and autophagy were concurrently processed following PDT (7).

The complexity in the schedule of caspase activation and autophagy induction was revealed at the conditions of a strong PDT insult $(\mathrm{LD} \geq 90 \%)$. It has been suggested by Kessel et al (34) that a high PDT-dose $\left(\mathrm{LD}_{90}\right)$ can damage proteins involved in the autophagic process and thus are unable to promote autophagy, contrary to a low dose leading to $5 \%$ of cell death that rapidly induced an autophagic response. With time, cells that escape the rapid apoptotic death induced by high PDT-dose may recover the ability to develop autophagy (34). Reiners and co-workers (9) have evidenced that at the higher-light dose, caspase activation preceded autophagosome formation, whereas at the lower-light dose procaspase activation paralleled autophagosome formation. Fig. 3 depicted an immediate release of cyt $C$ followed by caspase -9 and -7 activation at $1 \mathrm{~h}$ post-PDT presuming early mitochondrial photodamage probably due to the non-negligible part of mTHPC extracted from this organelle (21). The loss of mitochondria cyt $\mathrm{C}$ correlates with a previously observed accumulation of cytosolic cyt $\mathrm{C}$ upon mTHPC-PDT treatment of MCF-7 cells (21). With increase in post-PDT incubation, the cyt $C$ release and caspase- 9 activation declined. On the contrary, the cleavage of caspase-7 was maintained (Fig. 3). These events correlated with an induction of ER oxidative stress evidenced by an increase in the expression of GRP78. Weak mitochondrial damage along with significant caspase-7 activation at the time of GRP78 induction has been described (21). These observations support the assumption of a strong relationship between GRP78 and caspase-7 $(35,36)$. The occurrence of LC3-II expression at the time corresponding to GRP78 induction suggests that photo-induced autophagy could be related to ER stress. However, additional experiments with siRNA to inhibit GRP78 are warranted before the final conclusion can be drawn. Photodamage to the ER produced by PDT was argued as a main causal event in the induction of autophagy $(7,34)$ and recently, autophagy has been shown to require the unfolded protein response (UPR) signalling pathway regulated by GRP78 $(37,38)$. Several recent studies have outlined the capability of ER stress to engage both the apoptotic and the autophagy machineries (review in ref. 38). In our cell model, since caspase-7 remained active and thus, could hamper autophagy induction, no clear relationship could be established between the induction of GRP78 and the increase in LC3-II expression. However, Reiners et al reported that apoptosis-defective cells exhibit enhanced autophagic responses and sensitivity to killing in PDT protocols employing ER and mitochondrial photosensitizers (9). The treatment with protease inhibitors did not change LC3-II expression (data not shown), suggesting that mTHPC-PDT blocks LC3-II degradation and therefore inhibits the later steps of the autophagic pathway. This observation is consistent with mTHPC-PDT treatment of another cell line (20).

As expected, the use of Z-VAD-FMK resulted in a complete inhibition of both caspases- 9 and -7 but also in modifications of LC3 expression (Fig. 4A-C). Partial restoration of LC3-I expression, accumulation of LC3-II in control cells and decrease in LC3-II conversion at the highest PDT-dose (Fig. 4C) suggested that Z-VAD-FMK, being a protease inhibitor, could interact with the autophagic process by blocking the LC3-II degradation causing an accumulation of late autophagic vacuoles $(39,40)$. In fact, Z-VAD was found to be a potent inhibitor of cathepsin B, although to a lesser extent than two known cathepsin inhibitors (E64d and pepstatin A) (39). However, the non-influence of Z-VAD-FMK on cell toxicity (Fig. 4D) confirmed earlier observations of the suppression of apoptosis whereas autophagy was preserved not protecting from cytotoxicity after PDT $(19,41)$. According to our data on flow cytometry evaluation of Sub-G1 in caspase-3 deficient MCF-7 cells, apoptotic cell death does not exceed 10-15\%. At the same time, the autophagy inhibition by Wortmannin decreased photocytotoxicity (Fig. 5E) with a simultaneous enhancement of caspases- 9 and -7 activation and the subsequent cleavage of PARP (Fig. 5B-D). A significant decrease in toxicity in the presence of a specific autophagy inhibitor shows a valuable contribution of autophagy to cell phototoxicity in mTHPCphotosensitized MCF-7 cells, although the post-mitochondrial apoptotic pathway is active. If caspase-7 correlates to apoptosis, then the decrease in photoinduced cell toxicity in the presence of Wortmannin at the observed increased activities of caspase -7 is unexpected. However, one should keep in mind that MTHPC is a strong photo-inducer of necrosis (30) with a minor contribution of apoptosis and as such the inhibition of this process does not contribute significantly to cell phototoxicity. It has been suggested that autophagy plays a prodeath role in PDT-mediated killing in apoptosis-defective cells $(7,9)$, or in cells exhibiting a slow apoptotic response $(6,42)$.

\section{Acknowledgments}

This work was supported by Alexis Vautrin Cancer Center Research Funds, French Ligue Nationale contre le Cancer. We gratefully acknowledge Biolitec AG for providing the mTHPC. 


\section{References}

1. Dougherty TJ: An update on photodynamic therapy applications. J Clin Laser Med Surg 20: 3-7, 2002.

2. Whitacre CM, Satoh TH, Xue L, Gordon NH and Oleinick NL: Photodynamic therapy of human breast cancer xenografts lacking caspase-3. Cancer Lett 179: 43-49, 2002.

3. Oleinick NL, Morris RL and Belichenko I: The role of apoptosis in response to photodynamic therapy: what, where, why, and how. Photochem Photobiol Sci 1: 1-21, 2002.

4. Agostinis P, Buytaert E, Breyssens H and Hendrickx N: Regulatory pathways in photodynamic therapy induced apoptosis. Photochem Photobiol Sci 3: 721-729, 2004.

5. Buytaert E, Dewaele M and Agostinis P: Molecular effectors of multiple cell death pathways initiated by photodynamic therapy. Biochim Biophys Acta 1176: 86-107, 2007.

6. Andrzejak M,Price M and Kessel DH: Apoptotic and autophagic responses to photodynamic therapy in 1clc7 murine hepatoma cells. Autophagy 7: Sep 1, 2010 (Epub ahead of print).

7. Buytaert E, Callewaert G, Hendrickx N, et al: Role of endoplasmic reticulum depletion and multidomain proapoptotic BAX and BAK proteins in shaping cell death after hypericin-mediated photodynamic therapy. FASEB J 20: 756-758, 2006.

8. Kessel D, Vicente MG and Reiners JJ Jr: Initiation of apoptosis and autophagy by photodynamic therapy. Lasers Surg Med 38: $482-488,2006$

9. Reiners JJ Jr, Agostinis P, Berg K, Oleinick NL and Kessel D: Assessing autophagy in the context of photodynamic therapy. Autophagy 6: 7-18, 2010.

10. Xue LY, Chiu SM, Azizuddin K, Joseph S and Oleinick NL: The death of human cancer cells following photodynamic therapy: apoptosis competence is necessary for Bcl-2 protection but not for induction of autophagy. Photochem Photobiol 83: 1016-1023, 2007.

11. Rosenfeldt MT and Ryan KM: The multiple roles of autophagy in cancer. Carcinogenesis: Feb 11, 2011 (Epub ahed of print).

12. Codogno P and Meijer AJ: Autophagy and signaling: their role in cell survival and cell death. Cell Death Differ 12: 1509-1518, 2005.

13. Chen F, Wang CC, Kim E and Harrison LE: Hyperthermia in combination with oxidative stress induces autophagic cell death in HT-29 colon cancer cells. Cell Biol Int 32: 715-723, 2008.

14. Chen Y, McMillan-Ward E, Kong J, Israels SJ and Gibson SB: Oxidative stress induces autophagic cell death independent of apoptosis in transformed and cancer cells. Cell Death Differ 15 $171-182,2008$

15. Scherz-Shouval R and Elazar Z: ROS, mitochondria and the regulation of autophagy. Trends Cell Biol 17: 422-427, 2007.

16. Valencia A and Moran J: Reactive oxygen species induce different cell death mechanisms in cultured neurons. Free Radic Biol Med 36: 1112-1125, 2004

17. Yorimitsu T, Nair U, Yang Z and Klionsky DJ: Endoplasmic reticulum stress triggers autophagy. J Biol Chem 281: 30299-30304, 2006.

18. Ferraro E and Cecconi F: Autophagic and apoptotic response to stress signals in mammalian cells. Arch Biochem Biophys 462 210-219, 2007.

19. Kessel D and Arroyo AS: Apoptotic and autophagic responses to Bcl-2 inhibition and photodamage. Photochem Photobiol Sci 6 : 1290-1295, 2007.

20. Sasnauskiene A, Kadziauskas J, Vezelyte N, Jonusiene V and Kirveliene V: Apoptosis, autophagy and cell cycle arrest following photodamage to mitochondrial interior. Apoptosis 14 276-286, 2009

21. Marchal S, Francois A, Dumas D, Guillemin F and Bezdetnaya L: Relationship between subcellular localisation of Foscan and caspase activation in photosensitised MCF-7 cells. Br J Cancer 96: 944-951, 2007

22. Teiten MH, Marchal S, D'Hallewin MA, Guillemin F and Bezdetnaya L: Primary photodamage sites and mitochondrial events after Foscan photosensitization of MCF-7 human breast cancer cells. Photochem Photobiol 78: 9-14, 2003.
23. Kabeya Y, Mizushima N, Ueno T, et al: LC3, a mammalian homologue of yeast Apg8p, is localized in autophagosome membranes after processing. EMBO J 19: 5720-5728, 2000.

24. Karim MR, Kanazawa T, Daigaku Y, Fujimura S, Miotto G and Kadowaki M: Cytosolic LC3 ratio as a sensitive index of macroautophagy in isolated rat hepatocytes and H4-II-E cells. Autophagy 3: 553-560, 2007.

25. Mizushima N: Methods for monitoring autophagy. Int J Biochem Cell Biol 36: 2491-2502, 2004

26. Bampton ET, Goemans CG, Niranjan D, Mizushima N and Tolkovsky AM: The dynamics of autophagy visualized in live cells: from autophagosome formation to fusion with endo/ lysosomes. Autophagy 1: 23-36, 2005.

27. Biederbick A, Rose S and Elsasser HP: A human intracellular apyrase-like protein, LALP70, localizes to lysosomal/autophagic vacuoles. J Cell Sci 112: 2473-2484, 1999.

28. Blommaart EF, Krause U, Schellens JP, Vreeling-Sindelarova $\mathrm{H}$ and Meijer AJ: The phosphatidylinositol 3-kinase inhibitors wortmannin and LY294002 inhibit autophagy in isolated rat hepatocytes. Eur J Biochem 243: 240-246, 1997.

29. Lockshin RA and Zakeri Z: Apoptosis, autophagy, and more. Int J Biochem Cell Biol 36: 2405-2419, 2004.

30. Marchal S, Fadloun A, Maugain E, D'Hallewin MA, Guillemin F and Bezdetnaya L: Necrotic and apoptotic features of cell death in response to Foscan ${ }^{\circledR}$ photosensitization of HT29 monolayer and multicell spheroids. Biochem Pharmacol 69: 1167-1176, 2005.

31. Bressenot A, Marchal S, Bezdetnaya L, Garrier J, Guillemin F and Plenat F: Assessment of apoptosis by immunohistochemistry to active caspase- 3 , active caspase-7, or cleaved PARP in monolayer cells, spheroid, and subcutaneous xenografts of human carcinoma. J Histochem Cytochem 57: 289-300, 2009.

32. Klionsky DJ, Abeliovich H, Agostinis P, et al: Guidelines for the use and interpretation of assays for monitoring autophagy in higher eukaryotes. Autophagy 4: 151-175, 2008.

33. Xu Y, Kim SO, Li Y and Han J: Autophagy contributes to caspase-independent macrophage cell death. J Biol Chem 281: 19179-19187, 2006.

34. Kessel D and Reiners JJ Jr: Apoptosis and autophagy after mitochondrial or endoplasmic reticulum photodamage. Photochem Photobiol 83: 1024-1028, 2007.

35. Reddy RK, Mao C, Baumeister P, Austin RC, Kaufman RJ and Lee AS: Endoplasmic reticulum chaperone protein GRP78 protects cells from apoptosis induced by topoisomerase inhibitors: role of ATP binding site in suppression of caspase-7 activation. J Biol Chem 278: 20915-20924, 2003.

36. Lee AS: GRP78 induction in cancer: therapeutic and prognostic implications. Cancer Res 67: 3496-3499, 2007.

37. Li J, Ni M, Lee B, Barron E, Hinton DR and Lee AS: The unfolded protein response regulator $\mathrm{GRP} 78 / \mathrm{BiP}$ is required for endoplasmic reticulum integrity and stress-induced autophagy in mammalian cells. Cell Death Differ 15: 1460-1471, 2008.

38. Verfaillie T, Salazar M, Velasco G and Agostinis P: Linking ER stress to autophagy: potential implications for cancer therapy. Int J Cell Biol 2010: 930509, 2010.

39. Wu YT, Tan HL, Huang Q, et al: Autophagy plays a protective role during zVAD-induced necrotic cell death. Autophagy 4: 2008.

40. Cao C, Subhawong T, Albert JM, et al: Inhibition of mammalian target of rapamycin or apoptotic pathway induces autophagy and radiosensitizes PTEN null prostate cancer cells. Cancer Res 66 : 10040-10047, 2006.

41. Chiu SM, Xue LY, Usuda J, Azizuddin K and Oleinick NL: Bax is essential for mitochondrion-mediated apoptosis but not for cell death caused by photodynamic therapy. Br J Cancer 89: 1590-1597, 2003.

42. Xue LY, Chiu SM and Oleinick NL: Atg7 deficiency increases resistance of MCF-7 human breast cancer cells to photodynamic therapy. Autophagy 6: 248-255, 2011. 